\title{
FLAVONOIDS OF THE GENUS Crataegus
}

\section{THE STRUCTURE OF BIOQUERCETIN}

V. I. Bykov, V. I, Glyzin,

UDC 547.972

and A. I. Ban'kovskii

Continuing a study of the flavonoid composition of plants of the genus Crataegus (hawthorne), from the leaves of $C$. pinnatifida Bge. we have isolated a compound with the composition $\mathrm{C}_{27} \mathrm{H}_{30} \mathrm{O}_{16} \cdot 1 /{ }_{2} \mathrm{H}_{2} \mathrm{O}, \mathrm{mp}$ 194$199^{\circ} \mathrm{C},[\alpha]_{\mathrm{D}}^{20}-34.8^{\circ}, \lambda_{\max } 362,258 \mathrm{~nm}$.

The IR spectrum of the substance shows absorption bands due to the stretching vibrations of a hydroxy group (3350 $\mathrm{cm}^{-1}$, broadened peak), of a carbonyl group $\left(1655 \mathrm{~cm}^{-1}\right)$, and of conjugated double bonds $\left(1605,1585,1504 \mathrm{~cm}^{-1}\right)$. The IR spectra taken with the use of diagnostic reagents shows the presence of free hydroxy groups in it at $\mathrm{C}_{5}, \mathrm{C}_{7}, \mathrm{C}_{3}{ }^{\prime}$, and $\mathrm{C}_{4}{ }^{\prime}$.

The acid hydrolysis of the flavonoid gave quercetin $\mathrm{C}_{15} \mathrm{H}_{10} \mathrm{O}_{7}, \mathrm{mp} 308-313^{\circ} \mathrm{C}, \lambda \max 375,256 \mathrm{~nm}$. As sugar components, galactose and rhamnose were identified by paper chromatography in the benzene-butan1-ol-pyridine-water $(1: 5: 3: 3)$ system [1].

The spectral characteristics of the glycoside and its aglycone show that the carbohydrate moiety is present in the form of a biose in position 3 .

The constants of the substance and the products of its hydrolysis correspond to bioquercetin, for which the structure of quercetin 3-O-[ $\beta-\mathrm{L}-$ rhamnopyranosyl- $(1 \rightarrow 6)-\beta-\mathrm{D}-\mathrm{galactofuranoside}]$ has been suggested [2].

In the NMR spectrum of the silylated glycoside there are the following signals (ppm): quartet with its center at $7.65,1 \mathrm{H}, \mathrm{J}=2.5 \mathrm{~Hz}$, and $\mathrm{J}^{\prime}=9 \mathrm{~Hz}\left(\mathrm{H}-6^{\prime}\right)$; doublet at $7.22,1 \mathrm{H}, \mathrm{J}=2.5 \mathrm{~Hz}\left(\mathrm{H}-2^{\prime}\right)$; doublet at 6.75 , $1 \mathrm{H}, \mathrm{J}=9 \mathrm{~Hz}\left(\mathrm{H}^{-} 5^{\prime}\right)$, doublet at $6.37 \mathrm{ppm}, 1 \mathrm{H}, \mathrm{J}=2.5 \mathrm{~Hz}(\mathrm{H}-8)$; doublet at $6.06,1 \mathrm{H}, \mathrm{J}=2.5 \mathrm{~Hz}(\mathrm{H}-6)$; doublet at $5.56,1 \mathrm{H}, J=8 \mathrm{~Hz}$ (proton of the anomeric center of $\beta$-galactose in position 3 of the flavonol); doublet at $4.28 \mathrm{ppm}, 1 \mathrm{H}, \mathrm{J}=2 \mathrm{~Hz}$ (proton of the anomeric center of $\alpha$-rhamnose attached to the galactose in position 6); multiplet in the 3.20-3.80 ppm region, $10 \mathrm{H}$ (protons of the biose) [3].

Exhaustive methylation of the flavonoid with subsequent methanolysis of the ether formed led to the methyl glycosides of 2,3,4-tri-O-methyl-L-rhamnose and 2,3,4-tri-O-methyl-D-galactose, which were identified by gas-liquid chromatography from their relative retention times [4].

The results obtained show that in the compound isolated the galactose has the $\beta$ configuration of the glycosidic center and a pyranose ring and the rhamnose the $\alpha$ configuration and a pyranose ring. Thus, in our opinion, bioquercetin has the structure quercetin $3-\mathrm{O}-[\alpha-\mathrm{L}-$ rhamnopyranosyl- $(6 \rightarrow 1)-\beta-\mathrm{D}$-galactopyranoside].

\section{LIT ERATU RE CITED}

1. G. N. Zaitseva and T. P. Afanas'eva, Biokhimiya, 22, No. 6, 1035 (1957).

2. N. P. Maksyutina, Khim. Prirodn. Soedin., 226 (1967).

3. T. J. Mabry, K. R. Markham, and M. B. Thomas, The Systematic Identification of Flavonoids, Springer, New York (1970), pp. 64, 274.

4. J. O. Aspinall, J. Chem. Soc., 1676 (1963).

Khabarovsk State Medical Institute. All-Union Scientific-Research Institute of Medicinal Plants. Translated from Khimiya Prirodnykh Soed nenii, No. 4, pp. 557-558, July-August, 1973. Original article submitted F ebruary 14, 1973.

() 1975 Plenum Publishing Corporation, 227 West 17th Street, New York, N.Y. 10011. No part of this pullication may be reproduced, stored in a retrieval system, or transmitted, in any form or by any means, electronic, mechanical, photocopying, microfilming. recording or otherwise, without written permission of the publisher. A copy of this article is available from the publisher for $\$ 15.00$. 